\title{
Granulocyte macrophage colony- stimulating factor receptor a expression and its targeting in antigen-induced arthritis and inflammation
}

Andrew D. Cook ${ }^{1 *}$, Cynthia Louis ${ }^{1}$, Matthew J. Robinson ${ }^{2}$, Reem Saleh ${ }^{1}$, Matthew A. Sleeman ${ }^{2,3}$ and John A. Hamilton ${ }^{1}$

\begin{abstract}
Background: Blockade of granulocyte macrophage colony-stimulating factor (GM-CSF) and its receptor (GM-CSFRa) is being successfully tested in trials in rheumatoid arthritis (RA) with clinical results equivalent to those found with neutralization of the current therapeutic targets, TNF and IL-6. To explore further the role of GM-CSF as a proinflammatory cytokine, we examined the effect of anti-GM-CSFRa neutralization on myeloid cell populations in antigen-driven arthritis and inflammation models and also compared its effect with that of anti-TNF and anti-IL-6.

Methods: Cell population changes upon neutralization by monoclonal antibodies (mAbs) in the antigen-induced arthritis (AIA) and antigen-induced peritonitis (AIP) models were monitored by flow cytometry and microarray. Adoptive transfer of monocytes into the AIP cavity was used to assess the GM-CSF dependence of the development of macrophages and monocyte-derived dendritic cells (Mo-DCs) at a site of inflammation.

Results: Therapeutic administration of a neutralizing anti-GM-CSF mAb, but not of an anti-colony-stimulating factor (anti-CSF)-1 or an anti-CSF-1R mAb, ameliorated AIA disease. Using the anti-GM-CSFRa mAb, the relative surface expression of different inflammatory myeloid populations was found to be similar in the inflamed tissues in both the AIA and AIP models; however, the GM-CSFRa mAb, but not neutralizing anti-TNF and anti-IL-6 mAbs, preferentially depleted Mo-DCs from these sites. In addition, we were able to show that locally acting GM-CSF upregulated macrophage/Mo-DC numbers via GM-CSFR signalling in donor monocytes.
\end{abstract}

Conclusions: Our findings suggest that GM-CSF blockade modulates inflammatory responses differently to TNF and IL-6 blockade and may provide additional insight into how targeting the GM-CSF/GM-CSFRa system is providing efficacy in RA.

Keywords: Granulocyte macrophage colony-stimulating factor, Arthritis, Inflammation, Targeting, Macrophages, Animal models

\footnotetext{
* Correspondence: adcook@unimelb.edu.au

${ }^{1}$ Department of Medicine, Royal Melbourne Hospital, University of

Melbourne, Parkville, Victoria 3050, Australia

Full list of author information is available at the end of the article
} 


\section{Background}

Clinical trials assessing blockade of granulocyte macrophage colony-stimulating factor (GM-CSF) or its receptor (GM-CSFR $\alpha)$ have commenced in rheumatoid arthritis (RA), psoriasis, multiple sclerosis and asthma, with some encouraging RA data [1, 2]. Questions, such as which is the key cell type(s) regulated by GM-CSF and whether it has pro-survival, differentiation and/or activation functions, remain to be addressed. For example, there is debate as to whether during an inflammatory response differentiation of inflammatory, monocyte-derived dendritic cells (Mo-DCs) is GM-CSFdependent [3-9]. Given that anti-TNF and anti-IL-6 therapies have been successful in RA and that head-to-head trials between anti-GM-CSFR $\alpha$ and anti-TNF are ongoing [2], it would be useful to know how similar or not the biology of the pro-inflammatory activity of GM-CSF is to the respective biology of these other cytokines.

The basic unit structure of the dodecameric GM-CSF receptor (GM-CSFR) consists of a binding, cytokinespecific $\alpha$ subunit and a signaling $\beta$ subunit [10]. It has been reported that there is a significant increase in the number of GM-CSFR $\alpha$-subunit (GM-CSFR $\alpha$ ) positive synovial macrophages in the RA synovium and that GM-CSFR $\alpha$ neutralization suppresses disease activity in the murine collagen-induced arthritis model [11]. It would seem that a GM-CSFR $\alpha$ monoclonal antibody (mAb) may be a useful tool to define GM-CSFR $\alpha$ expression on GM-CSF-responsive cells driving an inflammatory response and to be able to compare the efficacy with an anti-ligand therapeutic strategy.

The murine monoarticular antigen-induced arthritis (AIA) model is a widely used inflammatory arthritis model and is characterized by infiltration of neutrophils and mononuclear cells, synovitis (pannus formation) and erosion of cartilage and bone, thus replicating several features similar to those in RA [12-17]. An advantage of the AIA model lies in the exactly defined initiation of the arthritis, elicited by antigen injection into the knee joint cavity [18]. Using either gene-deficient mice or antibody neutralization strategies it has been found that both TNF and IL-6 contribute to at least some extent to AIA progression [19-24]. As we have identified suppression of AIA disease and pain in $\mathrm{GM}^{-\mathrm{CSF}^{-/-}}$mice [25], this particular model may be useful for comparing the effects of its blockade on myeloid cell populations with that of TNF or IL-6.

The sterile peritoneal cavity is a convenient location to induce inflammation, to analyse inflammatory cell populations and to study the evolution of the inflammatory response on account of the easy access to the peritoneal exudate. We developed the antigen-induced peritonitis (AIP) model [26] because it has elements of both innate and acquired immunity and it follows a similar priming and challenge protocol with the same antigen as the AIA model. We therefore reasoned that it may represent a convenient surrogate model for this particular arthritis model in which to study changes in cell populations. We have shown that it also demonstrates GM-CSF dependence [27] and have begun to explore the mode of action of GM-CSF as a pro-inflammatory cytokine using this model [28].

We report here that GM-CSFR $\alpha$ blockade leads to myeloid population changes in AIA and AIP, which differ to those observed with TNF or IL- 6 blockade. Additionally, we show that an anti-GM-CSFR $\alpha$ mAb can be used to directly monitor surface GM-CSFR $\alpha$ expression by flow cytometry and that its administration can lead to similar effects on myeloid cell populations as ligand neutralization at a site of inflammation, including preferential reduction in Mo-DCs.

\section{Methods \\ Mice}

C57BL/6 mice (both CD45.1 and CD45.2) were obtained from WEHI, Kew (Victoria, Australia). Csf1r-EGFP (MacGreen) mice [29], backcrossed onto the C57BL/6 background, are bred in our on-site animal facility at the University of Melbourne. Mice deficient in both $\beta c$ and $\beta_{\mathrm{IL}-3}$ [30], referred to here as $C s f 2 r b^{-/-} C s f 2 r b 2^{-/-}$mice, backcrossed onto the C57BL/6 background, were supplied by A. Lopez (Hanson Institute, Adelaide, Australia). Mice were fed standard rodent chow and water ad libitum. Mice of both sexes, aged 8-12 weeks, were used; experiments were approved by The University of Melbourne Animal Ethics Committee.

\section{Antigen-induced models}

Antigen-induced arthritis (AIA) was induced as previously described using methylated BSA (mBSA) as antigen [25]. Briefly, mice were immunized with mBSA (Sigma-Aldrich, St Louis, MO, USA), emulsified in complete Freund's adjuvant (CFA), intradermally in the base of the tail on day -7 and arthritis was induced 7 days later (day 0) by an intra-articular (i.a.) injection of mBSA into the right knee, the left knee being injected with PBS. Histological analysis was performed on the knee joints, which were scored separately $(0-3)$ for cellular infiltration, cartilage damage and bone erosion (H\&E stain), and proteoglycan loss (Safranin O/fast green stain) [25].

Antigen-induced peritonitis (AIP) was induced as previously described again using mBSA [28]. Briefly, mice were immunized intradermally with $\mathrm{mBSA}$, emulsified in CFA, as described for the AIA model above; 14 days later, the primary immunization protocol was repeated as a boost. Seven days later, mice were injected 
intraperitoneally (i.p.) with $200 \mu \mathrm{g}$ mBSA to induce peritonitis (day 0 ).

\section{mAb treatment}

Mice were treated i.p. with $150 \mu \mathrm{g}$ anti-GM-CSF (22E9.11, J. Abrams) [28], $250 \mu \mathrm{g}$ anti-CSF-1R (ASF98, S-I Nishikawa) [28], $150 \mu \mathrm{g}$ anti-CSF-1 (F. Dodeller, MorphoSys, Munich, Germany) [28, 31], $750 \mu$ g anti-GMCSFR $\alpha$ (CAM-3003) [11], $750 \mu \mathrm{g}$ anti-TNF (MP6-XT22, Biolegend, San Diego, CA, USA), $750 \mu \mathrm{g}$ anti-IL-6 (Biolegend) and their respective isotype control $\mathrm{mAb}$, at the time points indicated.

\section{Cell isolation and fluorescence-activated cell sorting (FACS) analysis}

Cell suspensions were prepared from the synovium or peritoneal cavity and analysed by flow cytometry [28, 32, 33]. For synovial cells, mice were perfused with $20 \mathrm{ml}$ PBS and the patellae from the knee joints were dissected and the synovium digested $(1 \mathrm{mg} / \mathrm{ml}$ collagenase type IV, $0.5 \mathrm{mg} / \mathrm{ml}$ neutral protease, $50 \mu \mathrm{g} / \mathrm{ml}$ DNase I in PBS) for 45 minutes at $37{ }^{\circ} \mathrm{C}$, then passed through a 70- $\mu \mathrm{m}$ nylon mesh to obtain a single cell suspension. Cells were washed twice in PBS, followed by cell counting using BD Trucount tubes (BD Biosciences). Joint cells were incubated with Fc block (anti-CD16/32, clone 2.4G2) and stained using the following antibodies: APC-Cy7conjugated CD45 (30-F11), BV421-conjugated CD11b (M1/70), PE-Cy7-conjugated CD11c (N418), BV510conjugated I-A/I-E (M5/114.15.2), FITC-conjugated Gr-1 (RB6-8C5), PE-conjugated F4/80 (BM8) and APCconjugated GM-CSFR $\alpha$ (CAM-3003). Note that Gr-1 was used for staining synovial cells rather than Ly6G and Ly6C due to the number of available channels.

Peritoneal cells were collected by lavage with $5 \mathrm{ml}$ cold PBS, followed by washing in PBS and cell counting using either trypan blue or BD Trucount tubes (BD Biosciences). Cells were incubated with Fc block (antiCD16/32, clone 2.4G2) and stained using the following antibodies: PE-conjugated CD115 (AFS98), PE-TxRed or PE-Cy7-conjugated CD11b (M1/70), BV421conjugated CD11c (HL3), BV510-conjugated I-A/I-E (M5/114.15.2), APC-Cy7 conjugated Ly6G (1A8), FITCor PE-Cy7-conjugated Ly6C (HK1.4), FITC-conjugated CD45.1 (A20), FITC-conjugated CD45.2 (104) and APC-conjugated GM-CSFR $\alpha$ (CAM-3003).

All fluorochrome-conjugated antibodies were sourced from BD Biosciences, Biolegend, or eBioscience, with the exception of $\alpha$ GM-CSFR $\alpha$ (CAM-3003) mAb. CAM-3003 was conjugated with APC using a Lightning-Link antibody labelling kit (Innova Biosciences) according to manufacturer's protocol. Cell viability was determined using 7-AAD (BD Biosciences) and data were acquired on a CyAn flow cytometer (Beckman Coulter). Compensation was acquired using single-stained samples and specificity of antibody staining was determined by the fluorescenceminus-one method. Analysis was performed using Kaluza 1.2 software (Beckman Coulter).

\section{Adoptive cell transfer}

Bone marrow was flushed from the tibias and femurs of donor mice, red blood cells lysed and $\mathrm{CD} 115^{+}$cells were either MACS-enriched, using CD115-Biotin antibody and anti-Biotin microbeads (Miltentyi Biotec), or FACS sorted. Monocyte purity after enrichment was $>90 \%$; $1.0 \times 10^{6}$ enriched monocytes were transferred i.p. into mBSA-challenged AIP mice on day 2.

\section{Gene expression analysis}

Total RNA was isolated (Qiagen) from total peritoneal exudate cells (PECs), magnetic bead-isolated CD $115^{+}$ PECs, or sorted CD $115^{+}$CD $45.1^{+}$donor PECs, from day 4 AIP. Individual gene expression was measured by RT-PCR using TaqMan Gene Expression Arrays (ThermoFisher). For transcriptomic analysis, RNA was quantified, normalised and verified by Bioanalyzer (Agilent) prior to processing onto Genechip Mouse Gene 2.0ST Microarrays (Affymetrix). Sorted CD115 donor PECs additionally underwent PCR amplification prior to analysis (Nugen). Normalisation across all arrays was achieved using the robust multi-array average (RMA) expression measure [34] which results in expression measures (summarised intensities) in log base 2. Significant genes from each comparison were analysed for enrichment of Kyoto Encyclopedia of Genes and Genomes (KEGG) pathway membership using a hypergeometric test. Pathway enrichment $(p<0.05)$ was assessed separately for upregulated and downregulated genes.

\section{Statistical analysis}

Data are expressed as mean \pm SEM. Statistical differences were assessed using the unpaired Student's $t$ test or one-way analysis of variance (ANOVA). For histologic scores, Kruskal-Wallis one-way ANOVA was used. $P \leq 0.05$ was considered statistically significant. In the microarray analysis, differentially expressed genes were defined as fold change $\geq 2$ with an adjusted $p$ value $<0.01$. Empirical Bayesian analysis was applied (including vertical within a given comparison) and the $p$ value was adjusted for multiple testing.

\section{Results}

GM-CSF, but not CSF-1, neutralization suppresses AIA

We have previously shown, using knockout mice, that AIA is partially dependent on GM-CSF [25]; however, this approach cannot delineate whether GM-CSF is acting during the antigen-priming, antigen-challenge (effector) and/or the more chronic inflammatory phase. Therefore to explore when GM-CSF might be acting in 
relation to AIA disease induction, we studied the effectiveness of both prophylactic and therapeutic treatment with a neutralizing anti-GM-CSF mAb (22E9). Treating AIA-primed mice prophylactically with anti-GM-CSF $\mathrm{mAb}$, on days -2 and 0 , led to some reduction in cell infiltration 3 days after AIA induction (day 0), as judged by histological analysis (H\&E stain) compared to isotype mAb treatment (Fig. 1a and b). There was also significantly less cartilage damage (H\&E stain) and proteoglycan loss (Safranin $\mathrm{O} /$ fast green stain) in the former group (Fig. 1a and b). Treating AIA-primed mice therapeutically on days 2 and 4 post AIA induction (day 0 ) led to a trend towards a reduction in cell infiltration and proteoglycan loss at day 7 and a significant reduction in the degree of cartilage damage and bone erosion compared to isotype-treated and PBS-treated AIAprimed mice (Fig. 1c and d). Treating mice with anti-GM-
CSF mAb on days 9 and 11 post AIA onset (chronic phase) had no effect on cell infiltration but did lead to a significant reduction in bone erosion and a trend towards a reduction in cartilage damage at day 14 compared to isotype-treated mice (data not shown). Thus, the earlier the anti-GM-CSF mAb treatment was started the more significant was the reduction in cell infiltration, while both prophylatic and therapeutic anti-GM-CSF mAb treatments resulted in reduced joint damage, i.e., GM-CSF blockade during either the acute or the more chronic phase of AIA ameliorated the structural changes.

We also assessed whether CSF-1, which acts more specifically on populations of the mononuclear phagocyte system (MPS) via CD115 (c-Fms) [35], is involved in AIA progression. AIA-primed mice were treated both prophylactically and therapeutically with an anti-CSF-1 $\mathrm{mAb}$; however, it had no effect on cell infiltration or

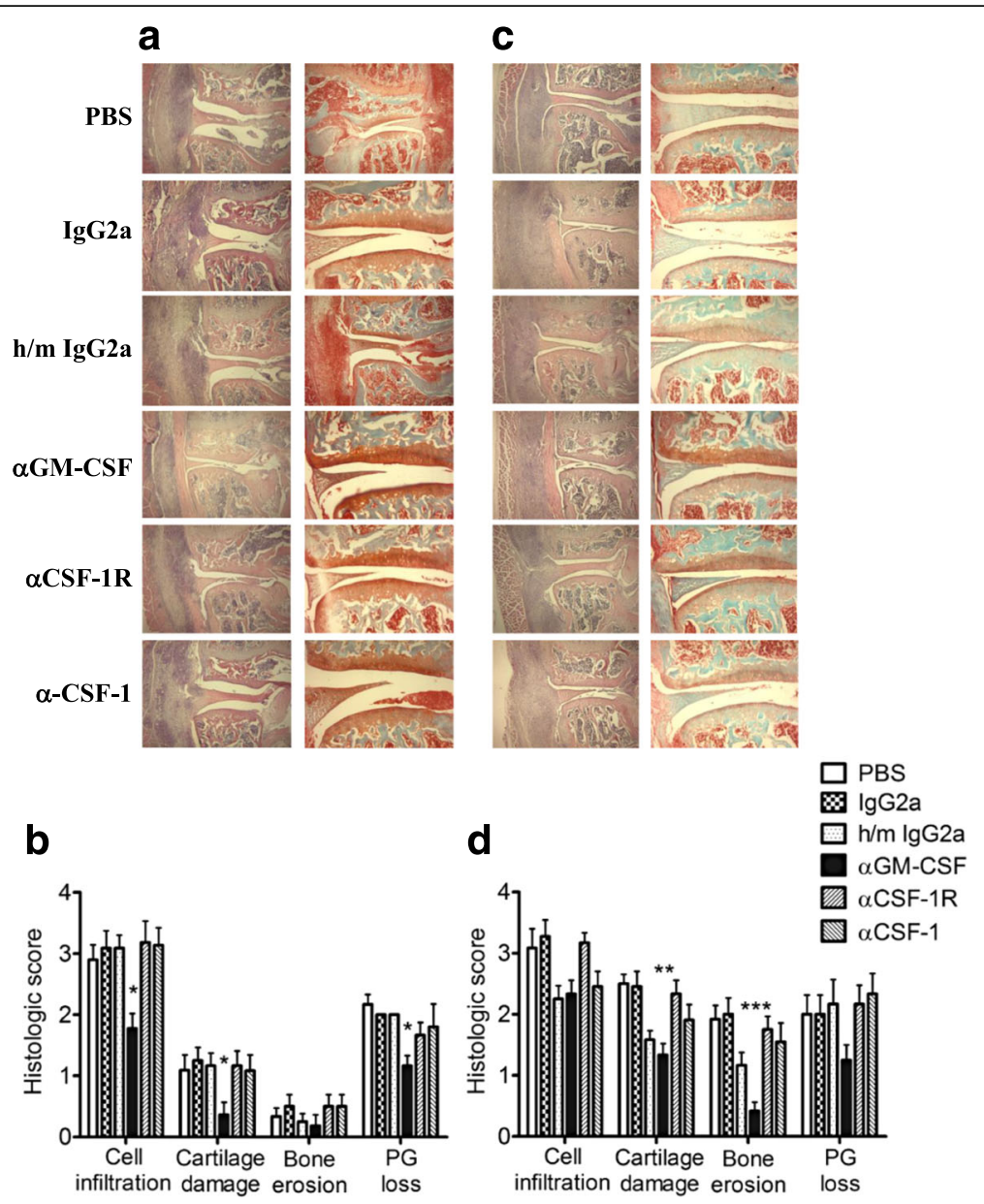

Fig. 1 Granulocyte macrophage colony-stimulating factor (GM-CSF) but not colony-stimulating factor (CSF-1) neutralization suppresses antigen-induced arthritis (AIA). AIA-primed mice were treated with PBS, anti-GM-CSF, anti-CSF-1R, anti-CSF-1 or isotype monoclonal antibodies, either prophylactically (days -2 and 0 ) (a and $\mathbf{b}$ ) or therapeutically (days 2 and 4) (c and $\mathbf{d}$ ), with arthritis being induced on day 0 by intra-articular injection of methylated bovine serum albumin (mBSA). Histological analysis of the arthritic joints was performed on day 3 (a and $\mathbf{b})$ and day 7 (c and $\mathbf{d}$ ) post arthritis induction. a, c Representative H\&E (left) and Safranin O/fast green (right) stained sections. b, d Quantification of histological appearances. PG proteoglycan. Data are expressed as mean \pm SEM, $n=6-12$ mice/group; ${ }^{*} p<0.05,{ }^{* *} p<0.01,{ }^{* * *} p<0.001$, anti-GM-CSF vs. PBS or lgG2a 
joint damage (Fig. 1a-d). As there is another ligand (IL-34) for the CSF-1R [1], we also tested an anti-CSF-1R mAb and obtained the same negative findings, suggesting that neither CSF-1 nor IL-34 is critical for AIA progression.

\section{GM-CSFRa expression and the effect of its blockade on myeloid cell populations in AIA}

It has been previously shown that in the synovial tissue of patients with RA there is a significant increase in GMCSFR $\alpha$-expressing cells and that the receptor is expressed by macrophages [11]. GM-CSFR $\alpha$ neutralization using the mAb, CAM-3003, was shown to be as effective as antiGM-CSF and anti-TNF mAbs in suppressing manifestations of murine collagen-induced arthritis, including the degree of synovial inflammation [11, 33, 36, 37]; the clinical benefit is also similar in RA trials using GMCSF receptor or GM-CSF neutralizing mAbs [2, 38]. For these and subsequent experiments we utilized the GM-CSFR $\alpha$ blocking mAb, CAM-3003, both as a neutralizing antibody in vivo and to detect GM-CSFR $\alpha$ expression by flow cytometry. This allowed us to study the expression of the receptor on specific cell populations at sites of inflammation and to verify that our experiments were not compromised by a lack of target coverage in the anti-GM-CSFR $\alpha$-treated mice, by assessing receptor occupancy simultaneously with the changes in their respective cell numbers.

Notwithstanding the challenges faced in defining categorically mononuclear phagocyte system (MPS) populations [28, 39-42], we first identified the different synovial myeloid populations, using a similar gating strategy to the one we previously published for the AIP model [28], with some notable modifications - the marker F4/80 was used in place of CD115 (CSF-1R) for analysis of the synovial macrophage/Mo-DC populations, as done by Weiss et al. [17], because surface CD115 could not be detected following tissue digestion and because we have previously shown that the CD $115^{+}$ populations in the inflamed AIP peritoneal cavity are also F4/80 ${ }^{+}$[28]. The gating strategy is provided in Fig. 2a using the following markers: $\mathrm{CD} 45^{+} \mathrm{F} 4 / 80^{-} \mathrm{CD} 11 \mathrm{~b}^{+} \mathrm{SSc}^{\text {int }}$ Gr- $1^{+}$neutrophils, $\mathrm{CD} 45^{+} \mathrm{F} 4 / 80^{+} \mathrm{CD} 11 \mathrm{~b}^{+} \mathrm{MPS}$ popula-

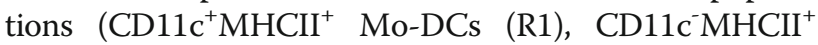
macrophages (R2), CD11 $\mathrm{c}^{-} \mathrm{MHCII}^{-}$macrophages (R3)), $\mathrm{CD} 5^{+} \mathrm{F} 4 / 80^{-} \mathrm{CD} 11 \mathrm{~b}^{+} \mathrm{SSc}^{\mathrm{lo}} \mathrm{Gr}-1^{+/-}$monocytes, $\mathrm{CD} 45^{+} \mathrm{F} 4 /$ $80^{-} \mathrm{CD}_{11 \mathrm{c}^{+}} \mathrm{MHCII}^{+}$conventional dendritic cells (cDCs) and $\mathrm{CD} 45^{+} \mathrm{F} 4 / 80^{\text {int }} \mathrm{SSc}^{\mathrm{hi}}$ eosinophils. Anti-Gr-1 mAb stains both Ly6G and Ly6C. We confirmed that the neutrophils were $\mathrm{Ly}_{6 \mathrm{G}}{ }^{+} \mathrm{Ly} 6 \mathrm{C}^{+}$, while the $\mathrm{F} 4 / 80^{-} \mathrm{CD} 11 \mathrm{~b}^{+} \mathrm{SSc} \mathrm{c}^{\text {lo }}$ monocytes were $\mathrm{Ly}_{6 \mathrm{G}}^{-}$and either $\mathrm{Ly}^{+} \mathrm{C}^{+}$or $\mathrm{Ly}^{-} \mathrm{C}^{-}$ (Additional file 1A). Furthermore, we showed that $\mathrm{Ly}_{6 G^{+}}$neutrophils were $\mathrm{CD} 64^{-}$and $\mathrm{F} 4 / 80^{+}$macrophages/Mo-DCs were CD64 ${ }^{+}$(Additional file 1B).
Following AIA induction there was an influx of CD45 cells into the joint, with neutrophils being the predominant cell type, comprising $50.5 \pm 1.6 \%$ of $C D 45^{+}$synovial cells at day 5. F4/80 ${ }^{+}$MPS populations (comprising Mo-DCs (R1) and $\mathrm{MHCII}^{+/-}$macrophages (R2 and R3, respectively) (Fig. 2a)) made up a further $17.6 \pm 2.0 \%$ of $\mathrm{CD} 45^{+}$synovial cells, with monocytes $(4.8 \pm 0.7 \%)$, eosinophils $(4.7 \pm 0.4 \%)$ and $\mathrm{cDCs}(0.6 \pm 0.1 \%)$ being minor populations. Using the CAM-3003 mAb, GMCSFR $\alpha$ was highly expressed on each of the F4/80 MPS populations, monocytes and cDCs (Fig. 2b) and further enhanced during inflammation, whereas on neutrophils and eosinophils its levels were low (Fig. 2b) and barely detectable above that of the isotype control (data not shown). AIA-primed mice were treated with the mAbs on days -1 and 2 (with i.a. challenge with mBSA again at day 0), and synovial cells were analysed once more on day 5 . This prophylactic treatment protocol was chosen as it covers the time period when cell infiltration into the joint is maximal, thus, allowing us to determine the effect of mAb blockade on the infiltrating cell populations. CAM-3003 treatment, but not that with the isotype control, CAT-004, reduced the levels of detectable GM-CSFR $\alpha$ on the F $4 / 80^{+}$MPS populations, monocytes and cDCs (Fig. 2b), suggesting that the availability of free receptor was reduced on these cell types. The low receptor levels on neutrophils and eosinophils meant that a similar analysis could not be conducted.

As regards changes in cell population numbers following prophylactic CAM-3003 treatment (days -1 and 2), there were significantly fewer Mo-DCs and eosinophils (vs. CAT-004 isotype control) in AIA mice at day 5 (Fig. 2c); there was also a trend towards fewer neutro-

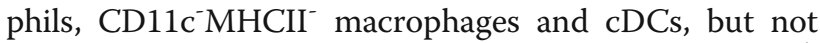
towards fewer $\mathrm{CD}_{11 \mathrm{c}^{-} \mathrm{MHCII}}^{+}$macrophages or $\mathrm{Gr}-1^{+/-}$ monocytes. Interestingly, as a proportion of $\mathrm{F} 4 / 80^{+}$cells, Mo-DCs were the only cell type to be significantly lower following CAM-3003 treatment indicating a preferential reduction (Fig. 2d). Gr-1 expression varied on the different $\mathrm{F} 4 / 80^{+}$subpopulations, with $66.6 \pm 4.3 \%$ of $\mathrm{CD} 11 \mathrm{c}^{-}$ $\mathrm{MHCII}^{-}$macrophages, $42.4 \pm 3.5 \% \mathrm{CD} 11 \mathrm{c}^{-} \mathrm{MHCII}^{+}$macrophages and $25.6 \pm 3.4 \%$ Mo-DCs being $\mathrm{Gr}-1^{+}$at day 5 . CAM-3003 treatment had no effect on the proportion of Gr $-1^{+}$cells in each MPS population $\left(69.0 \pm 3.0 \%\right.$ CD $11 c^{-}$ $\mathrm{MHCII}^{-}$macrophages, $45.2 \pm 2.8 \% \mathrm{CD} 11 \mathrm{c}^{-} \mathrm{MHCII}^{+} \mathrm{mac}^{-}$ rophages and $34.7 \pm 3.1 \%$ Mo-DCs) (data not shown).

TNF and IL- 6 have been implicated in AIA pathogenesis [19-24], and blocking antibodies against them have therapeutic effects in RA [43]. We reasoned that mechanistic comparisons between GM-CSFR $\alpha$ neutralization and that of these other pro-inflammatory cytokines may be informative. We therefore explored whether TNF or IL-6 blockade led to similar changes in AIA cell populations as GM-CSFR $\alpha$ blockade. As for the CAM-3003 


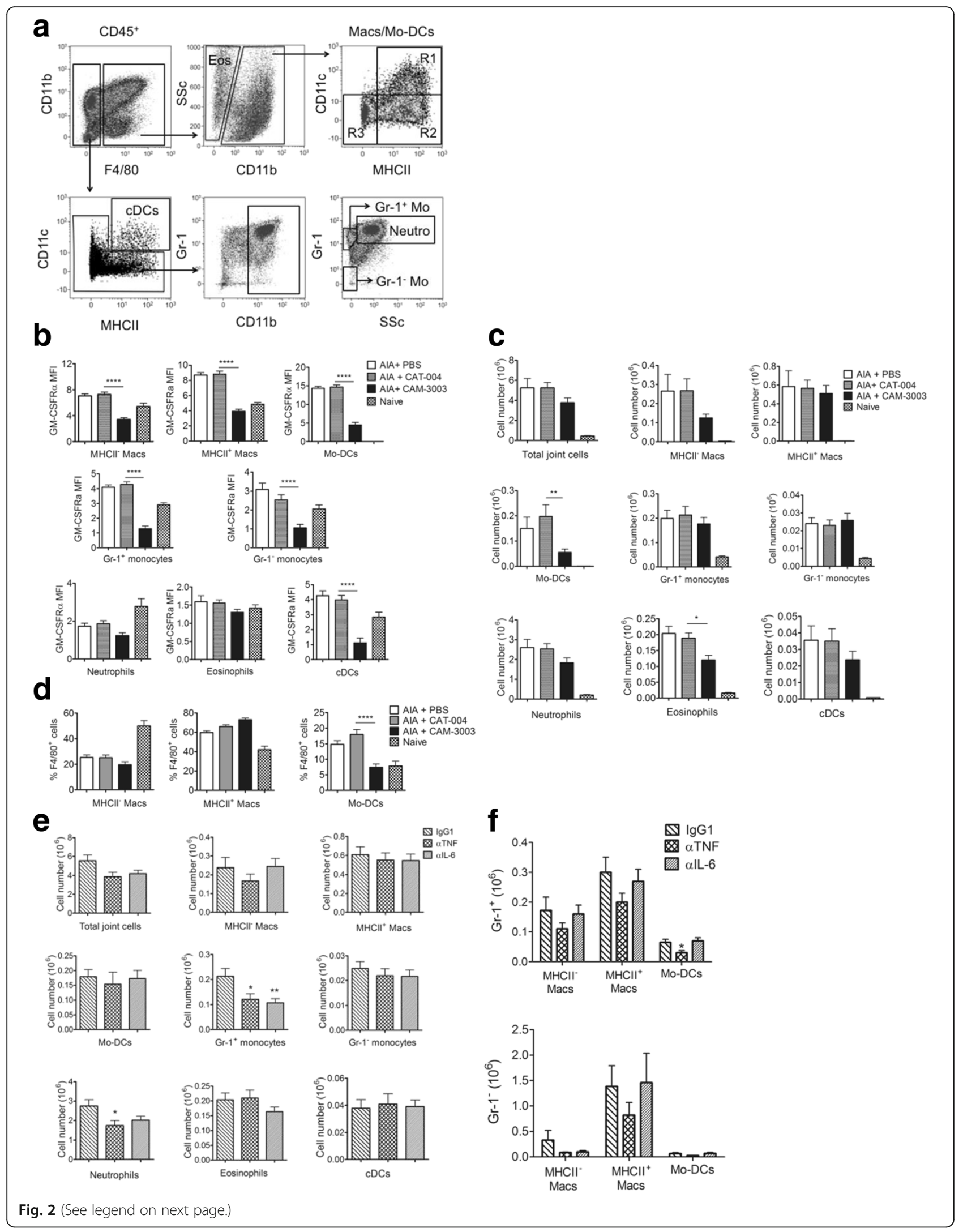




\begin{abstract}
(See figure on previous page.)
Fig. 2 Effect of granulocyte macrophage colony-stimulating factor receptor a (GM-CSFRa), TNF and IL-6 blockade on myeloid cell populations in antigen-induced arthritis (AIA). a Representative FACS plots showing the gating strategy used to identify CD45 $5^{+}$myeloid populations in the AIA

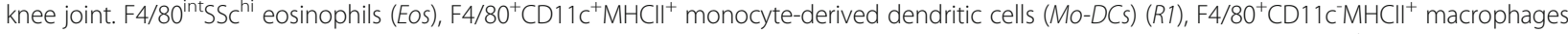

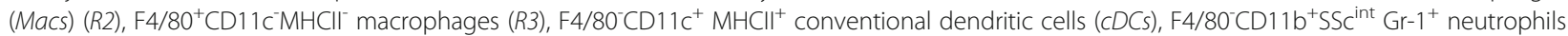
(Neutro) and F4/80 CD1 $1 \mathrm{~b}^{+} \mathrm{SSC}^{\mathrm{l}} \mathrm{Gr}-1^{+/-}$monocytes (Mo). b-d AlA-primed mice were treated with PBS, CAT-004 isotype monoclonal antibody (mAb) or CAM-3003 mAb on day -1 and day 2. Cells were harvested at day 5 post AIA induction and synovial populations analysed. b GM-CSFRa expression on myeloid cell populations. c Total $\mathrm{CD}_{4} 5^{+}$cells and myeloid cell populations. $\mathbf{d} \mathrm{MHCII}^{-}$macrophages, $\mathrm{MHCII}^{+}$macrophages and

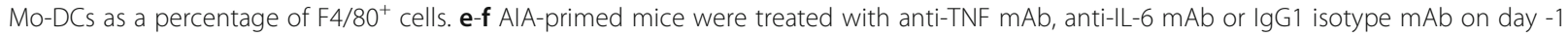
and day 2. Cells were harvested at day 5 post AIA induction and synovial populations analysed. e Total cells and myeloid cell populations. f Number of $\mathrm{Gr}-1^{+}$and $\mathrm{Gr}-1^{-}$cells in the different $\mathrm{F} 4 / 80^{+}$mononuclear phagocyte system (MPS) cell populations. Data are expressed as mean \pm SEM; $n=10-16$ mice/group; ${ }^{*} p<0.05,{ }^{* *} p<0.01,{ }^{* *} p<0.001,{ }^{* * *} p<0.0001$, CAT-004 vs. CAM-3003, or anti-TNF or anti-IL-6 vs. IgG1
\end{abstract}

protocol above, mice undergoing AIA were treated both before (day -1) and after (day 2) i.a. antigen challenge with anti-TNF or anti-IL-6 mAbs and their isotype control, with mice being killed at day 5 . There was a trend for fewer total cells and neutrophils (vs. IgG1 isotype control) in both anti-TNF-treated and anti-IL-6 treated AIA mice, being statistically significant for the latter cell type for anti-TNF mAb treatment (Fig. 2e), thus confirming previous findings [24, 44]. However, unlike CAM-3003-treated mice (Fig. 2c), no such significant decreases in cell numbers were noted for Mo-DCs or eosinophils following anti-TNF or anti-IL-6 mAb treatment (Fig. 2e).

There were also fewer synovial Gr- $1^{+}$monocytes following anti-TNF mAb (Fig. 2e). In line with this, following anti-TNF treatment, significantly fewer Mo-DCs were $\mathrm{Gr}-1^{+}$and there was a trend towards fewer $\mathrm{MHCII}^{-}$and $\mathrm{MHCII}^{+}$macrophages being $\mathrm{Gr}-1^{+}$ (Fig. 2f). The reduction in synovial $\mathrm{Ly} 6 \mathrm{C}^{+}$monocyte number also occurred in anti-IL-6-treated mice (Fig. 2e); however, this treatment did not affect the numbers of $\mathrm{Gr}-1^{+} \mathrm{F} 4 / 80^{+} \mathrm{MPS}$ populations (Fig. 2f). There were no differences in the numbers of $\mathrm{Gr}-1^{-} \mathrm{MPS}$ cells between any of the treatment groups (Fig. 2e and $\mathrm{f}$ ).

Thus, in AIA GM-CSFR $\alpha$ was most highly expressed on MPS cells and cDCs in the synovium; also administration of a neutralizing GM-CSFR $\alpha$ mAb variably reduced the synovial myeloid populations with a disproportionate effect on Mo-DCs amongst MPS populations. TNF and IL-6 neutralization had no significant effect on the numbers of synovial Mo-DCs and eosinophils, but reduced the numbers of synovial $\mathrm{Gr}-1^{+}$ monocytes.

\section{GM-CSFRa expression and the effect of its prophylactic blockade in AIP}

To characterize the effect of GM-CSFR $\alpha$ blockade on myeloid cells in greater detail we utilized our AIP model [28]. It should be noted that the protocol for induction of AIP is quite similar to AIA, except for the site of antigen (mBSA) challenge [25-28].
PEC populations were again analysed by flow cytometry. We again used CD115 [28, 32], when analysing PECs, given its specificity for macrophage-lineage cells amongst haemopoietic populations. The gating strategy was as before [28] (Additional file 2) using the following markers: $\mathrm{Ly}_{6 \mathrm{G}}{ }^{+}$neutrophils, Ly $6 \mathrm{G}^{-} \mathrm{CD} 115^{+}$monocytes/ macrophages/Mo-DCs (CD11c ${ }^{+} \mathrm{MHCII}^{+} \mathrm{Mo}-\mathrm{DCs}$ (R1),

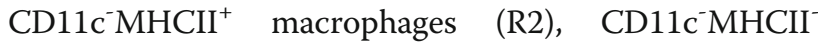
monocytes (R3)), CD115 $\mathrm{Ly}^{-} \mathrm{G}^{-} \mathrm{CD} 11 \mathrm{c}^{+} \mathrm{MHCII}^{+} \mathrm{cDCs}$ and CD115 Ly6G CD11b ${ }^{\text {int }} \mathrm{SSc}{ }^{\text {hi }}$ eosinophils. Note that, as previously [28], the $\mathrm{CD} 115^{+} \mathrm{CD} 11 \mathrm{c}^{-} \mathrm{MHCII}^{-}$cells (R3) in the inflamed peritoneal cavity are referred to as monocytes, based on their morphology and their being predominantly $\mathrm{Ly}^{+} \mathrm{C}^{+}$.

Following AIP induction, in PBS-treated mice at day 4 (the peak of the cellular response $[26,28]$ ) there was an influx of cells with $15.8 \pm 2.8 \%$ of exudate cells being neutrophils, $47.6 \pm 1.9 \% \mathrm{CD} 115^{+}$cells (monocytes, macrophages, Mo-DCs), $6.7 \pm 0.6 \%$ eosinophils and $2.6 \pm$ $0.2 \%$ cDCs. As for the synovial cells in the AIA model, the CAM-3003 mAb was able to detect GM-CSFR $\alpha$ on the MPS cells $\left(\mathrm{CD} 115^{+}\right)$and on cDCs (Fig. 3a), whereas again detection on neutrophils and eosinophils was difficult (low mean fluorescence intensity (MFI)) (Fig. 3a) and was barely above that of the isotype control (data not shown). Similar to what was shown for the AIA model (Fig. 2b), in the AIP model CAM-3003 treatment at day -1 , but not that with CAT-004, reduced the levels of detectable GM-CSFR $\alpha$ on the CD $115^{+}$cells and cDCs (Fig. 3a).

Upon prophylactic CAM-3003 administration (day -1), at day 4 there were also significantly fewer total PECs,

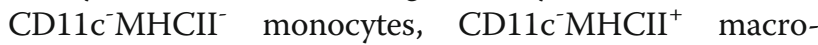
phages, Mo-DCs, neutrophils, eosinophils and cDCs with $30 \mathrm{mg} / \mathrm{kg}$ CAM3003 given i.p. (Fig. 3b), a dose found to be maximal - interestingly, the effect in general on cell population numbers was more pronounced than in the AIA model with data for the $\mathrm{CD}_{11 \mathrm{c}^{-} \mathrm{MHCII}}^{+}$peritoneal macrophages differing from the lack of effect of CAM-3003 shown above for the CD11c $\mathrm{MHCII}^{+}$synovial macrophages (Fig. 2c). As a proportion of CD115 cells, only the Mo-DCs were reduced following CAM- 


\section{a}
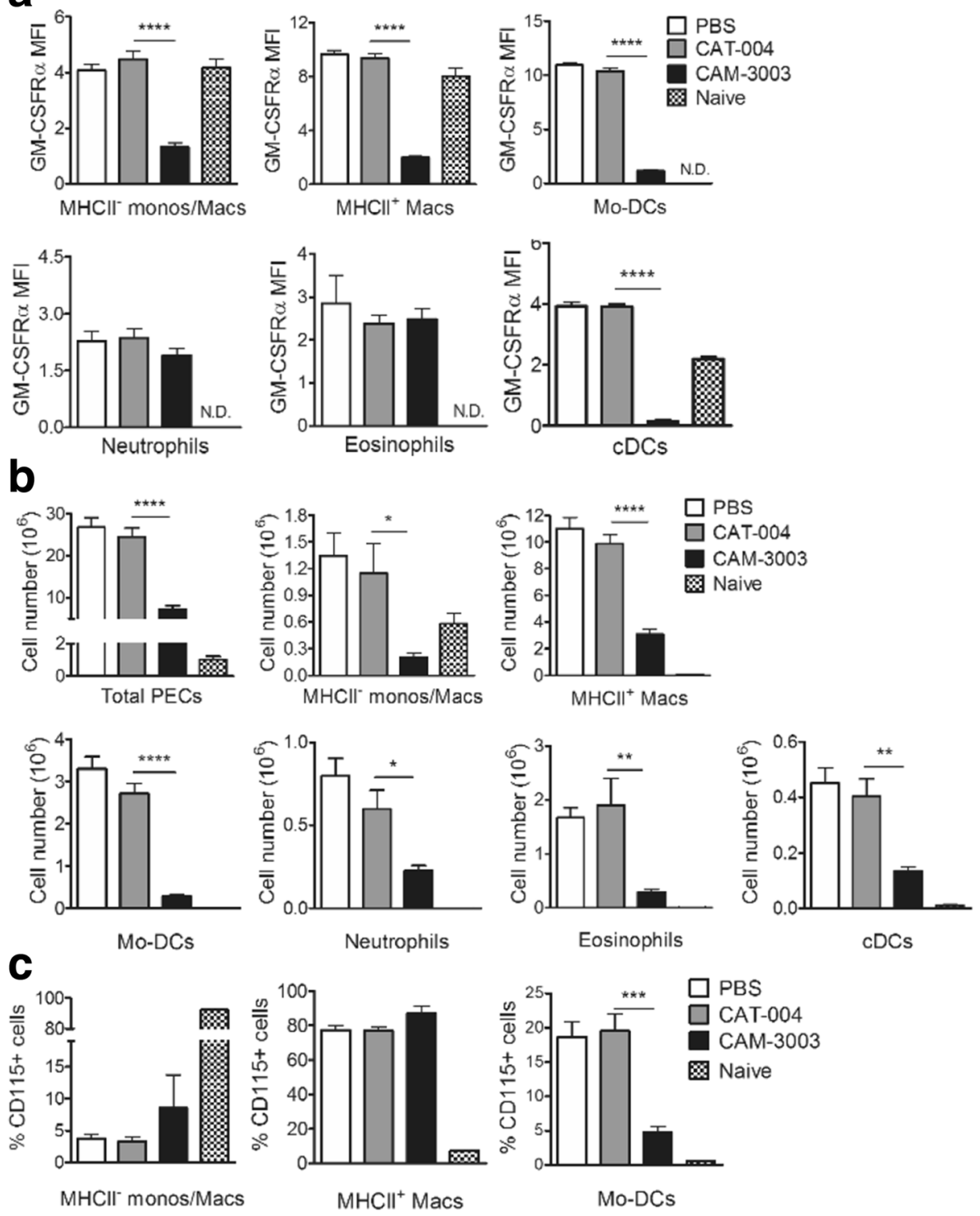

d
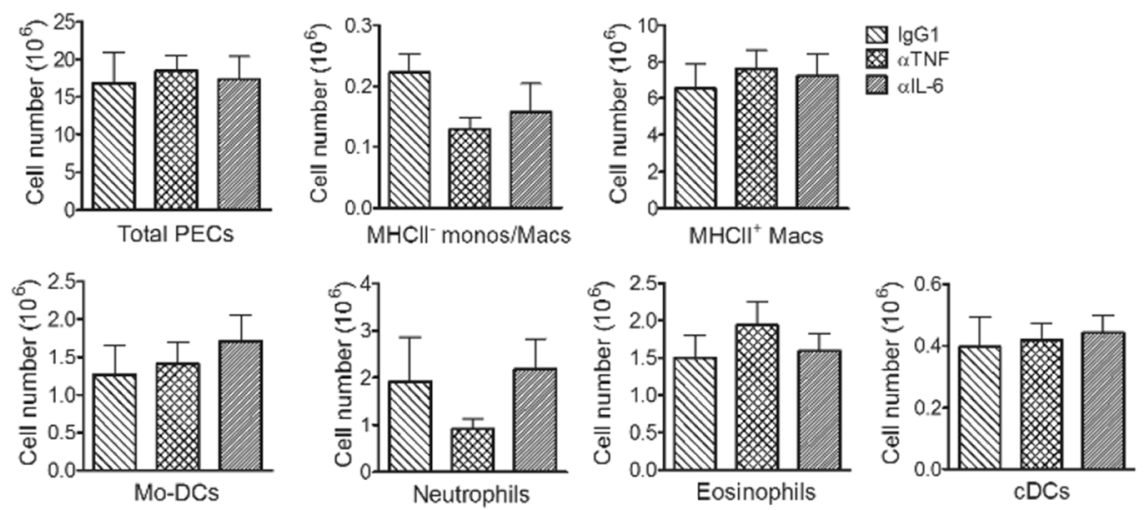

Fig. 3 (See legend on next page.) 
(See figure on previous page.)

Fig. 3 Effect of granulocyte macrophage colony-stimulating factor receptor a (GM-CSFRa), TNF and IL-6 blockade on myeloid cell populations in antigen-induced peritonitis (AIP). a-c AIP-primed mice were treated with PBS, CAT-004 isotype monoclonal antibody (mAb) or CAM-3003 mAb on day -1. Cells were harvested at day 4 post AIP induction and peritoneal exudate cell (PEC) populations analysed. a GM-CSFRa expression on myeloid cell populations. $\mathbf{b}$ Total cells and myeloid cell populations. c $\mathrm{MHCll}^{-}$monocytes/macrophages, $\mathrm{MHCI}^{+}$macrophages and monocyte-derived dendritic cells (Mo-DCs) as a percentage of CD115 cells. $\mathbf{d}$ AIP-primed mice were treated with anti-TNF mAb, anti-lL-6 mAb or lgG1 isotype mAb on day -1 and day 2. Cells were harvested at day 4 post AIP induction and PEC populations analysed. Total cells and myeloid cell populations are shown. Data are expressed as mean $\pm \mathrm{SEM} ; \mathrm{n}=8$ mice/group; ${ }^{*} \mathrm{p}<0.05,{ }^{* *} p<0.01,{ }^{* * *} p<0.001,{ }^{* * *} p<0.0001$ for CAT-004 vs. CAM-3003. CDCs conventional dendritic cells

3003 treatment once again indicating their preferential reduction (Fig. 3c), similar to that previously reported for the AIP model following blockade of GM-CSF [28] and to the data above for the AIA model (Fig. 2d). CAM-3003 treatment had no effect on the proportion of ${\text { Ly } 6 C^{+}}^{+}$cells within each CD $115^{+}$subpopulation (data not shown). Interestingly, the proportion of $\mathrm{MHCII}^{+}$macrophages and Mo-DCs in AIP which were $\mathrm{Ly}_{6} \mathrm{C}^{+}$was significantly lower than in AIA $\left(\mathrm{MHCII}^{+}\right.$macrophages: $21.7 \pm 2.3 \%$ vs. $38.6 \pm 3.1 \%$, Mo-DCs $4.0 \pm 0.4 \%$ vs. $24.4 \pm$ $1.5 \%$, AIP vs. AIA).

We next explored whether or not TNF or IL-6 blockade led to similar changes in AIP cell populations as GM-CSFR $\alpha$ blockade using a similar administration protocol. Mice undergoing AIP were treated before (day -1) i.p. antigen challenge, i.e., prophylactically, with antiTNF, anti-IL-6 mAbs or their isotype control, with mice killed at day 4; exudate cell populations were again analysed by flow cytometry. Unlike anti-GM-CSFR $\alpha$ (Fig. 3a), neither anti-TNF nor anti-IL-6 treatment had significant effects on myeloid population numbers (Fig. 3d), nor on detectable GM-CSFR $\alpha$ levels (data not shown), although there was a trend for fewer $\mathrm{MHCII}^{-}$monocytes/macrophages in anti-TNF-treated mice (Fig. 3d).

Thus, as in AIA, GM-CSFR $\alpha$ in AIP can be detected on certain myeloid populations and anti-GM-CSFR $\alpha$ administration led to a preferential reduction of Mo-DCs, indicating again the convenience of the AIP model in understanding the role of GM-CSF in inflammation. TNF and IL-6 neutralization had no significant effect on the numbers of different PEC populations compared to GM-CSFR $\alpha$ neutralization.

\section{Gene expression in PECs following GM-CSFRa blockade in the AIP model}

We repeated the above experiment with CAM-3003 and performed microarray analysis on purified $\mathrm{CD} 115^{+}$peritoneal cells (day 4) from the AIP cavity. As the majority of these cells would have derived from circulating monocytes [28], we first compared their gene expression to monocytes. Over 2000 genes were significantly different between these two populations $(\geq 2$ fold change in expression and adjusted $p$ value $<0.01$ ). However, only 12 genes were significantly changed between isotype-treated and CAM-3003 treated mice with this particular degree of stringency (Additional file 3). Although no genes were changed between isotype- and PBS-treated AIP mice, an additional 36 genes were found to be differentially expressed between the PBS and CAM-3003 groups (Additional file 3). Consequently, we performed pathway analysis on all the genes that differed between CAM3003-treated mice and the PBS-treated or isotypetreated mice. Using KEGG pathway enrichment analysis, the only pathways that were significantly changed were driven by one or two genes. Therefore GM-CSFR $\alpha$ blockade can by and large reduce the number of infiltrating myeloid cell populations, but had, at least at the day 4 time point in this model, a surprisingly minor impact on the CD $115^{+}$cell transcriptome (see "Discussion").

\section{Therapeutic blockade with anti-GM-CSFRa mAb in the AIP model}

In order to gain insight as to when GM-CSF signalling is required during an inflammatory reaction we next explored whether in the AIP model a therapeutic delivery (at day 2) of CAM-3003 after antigen challenge was effective and, if so, was it in anyway more effective if an additional prophylactic delivery (at day -1) was given, the latter protocol being similar to that employed above in the AIA model (Fig. 2). It can be seen that at day 4 the reductions in total PEC numbers and those of the various myeloid populations upon therapeutic treatment with CAM-3003 were similar to those noted if a pretreatment was incorporated in the protocol (Fig. 4), although a single treatment at day 2 did not lead to a significant reduction in neutrophils, in keeping with them being the predominant cell type early in an inflammatory response. Once again, detectable surface GMCSFR $\alpha$ levels were significantly lower on $\mathrm{CD}_{115^{+}}$cells and cDCs following both CAM-3003 treatment protocols (data not shown).

\section{Anti-GM-CSFRa mAb suppresses development of Mo-DCs from donor monocytes in the AIP cavity}

The above data in the AIA and AIP models suggests that GM-CSF signalling is most profoundly controlling the generation of Mo-DCs from monocyte precursors. To determine whether this GM-CSF-dependent phenotypic 

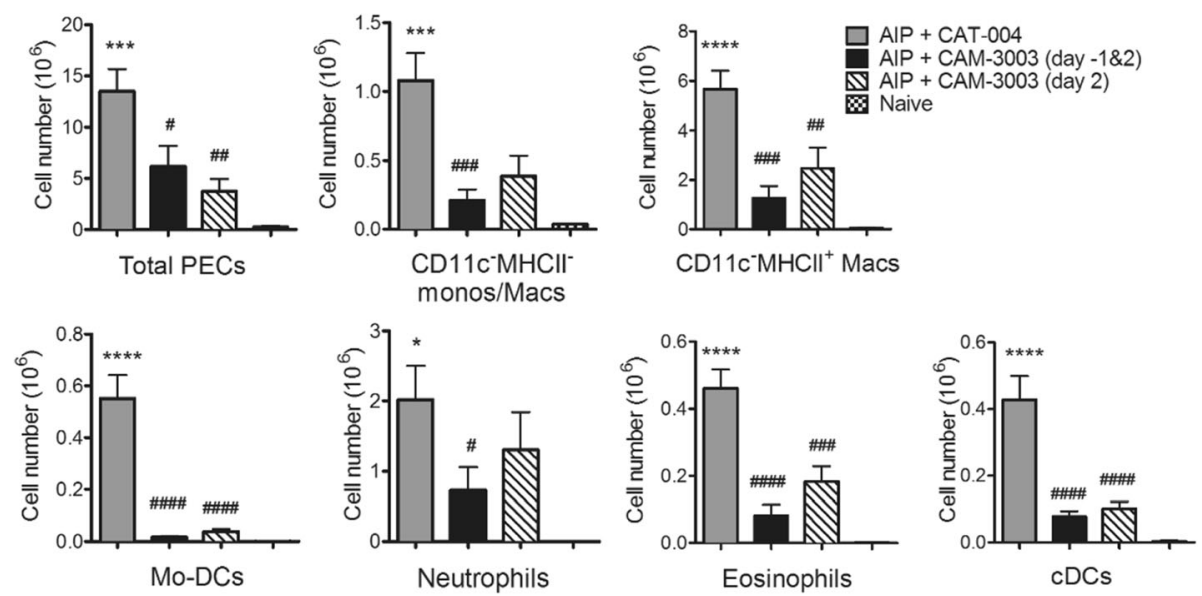

Fig. 4 Therapeutic blockade with anti-granulocyte macrophage colony-stimulating factor receptor a (anti-GM-CSFRa) monoclonal antibody $(\mathrm{mAb})$ in antigen-induced peritonitis (AIP). Peritoneal exudate cells (PECS) were harvested from naïve mice or day 4 after AIP induction from mice treated with CAT-004 (day -1 and day 2), CAM-3003 (day -1 and day 2) and CAM-3003 (day 2) and PEC populations were analysed (FACS). Data are

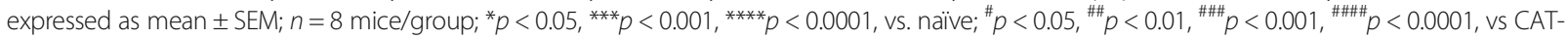
004. Mo-DCs monocyte-derived dendritic cells, CDCs conventional dendritic cells

change was actually occurring in recruited monocytes in the inflamed peritoneal cavity we injected MacGreen (Csf1R-EGFP) bone marrow monocytes [28] i.p. at day 2 into C57BL/6 wild-type (WT) recipient mice undergoing AIP, in the presence or absence of CAM-3003 - we previously used this monocyte donor approach to demonstrate the monocyte origin of the AIP $\mathrm{CD}_{115}{ }^{+}$exudate populations including Mo-DCs [28]. As above at day 4, as well as at day 3 , there were fewer total PECs, monocytes/macrophages (R2 and $\mathrm{R} 3\left(\mathrm{MHC}^{+/-}\right.$populations combined), Mo-DCs and cDCs if CAM-3003 was administered (Fig. 5a). Also, the percentage of $\mathrm{CD} 115^{+}$ cells that expressed $\mathrm{Ly}_{6} \mathrm{C}^{+}$declined over time but this decline was not altered by CAM-3003 (Fig. 5b). Again, detectable GM-CSFR $\alpha$ surface expression on the total CD $115^{+}$PECs was reduced by CAM-3003 (Fig. 5c).

For the total donor $\left(\mathrm{GFP}^{+}\right)$cells, fewer were retrieved from the cavity of CAM-3003-treated mice compared to CAT-004 isotype-treated mice (Fig. 5d). We could not detect donor cells in the draining lymph nodes consistent with there being a pro-survival effect of GM-CSF rather than an influence on cell migration (data not shown). There were significantly fewer donor Mo-DCs at days 3 and 4 in the CAM-3003-treated mice and a trend towards fewer donor monocytes/macrophages (R2 and R3 populations combined) on day 3, which reached significance on day 4 (Fig. 5e). Again the proportion of CD $115^{+}$donor cells converting into Mo-DCs was significantly reduced by CAM-3003 treatment (Fig. 5f); however, the loss of surface Ly6C was not affected (Fig. 5g). Interestingly, there appeared to be an increase over time in detectable surface GM-CSFR $\alpha$ in the donor monocytes (CAT-004-treated group, Fig. 5h).
Therefore, following transfer of monocytes directly into the inflamed peritoneum in the presence of CAM3003, the results suggest that the observed broad regulation in MPS and cDC numbers and the disproportionate impact on Mo-DCs can be driven by GM-CSF in the inflammatory milieu, although some additional impact on monocyte recruitment cannot be discounted.

\section{Transcriptome changes in donor $\mathrm{CD} 115^{+}$monocyte- derived populations following GM-CSFRa blockade in the AIP model}

We repeated the above monocyte transfer experiment using $\mathrm{CD} 115^{+} \mathrm{CD} 45.1$ congenic monocytes transferred into a CD45.2 host with very similar results (data not shown) - the donor-derived cells were then isolated and subjected to microarray analysis so that we could examine the effect of GM-CSF on the transcriptome of this population. Fewer genes were significantly changed compared with the experimental design shown in Additional file 3, with 889 genes changing between the transferred monocytes and those harvested after 2 days $\left(C D 45.1^{+}\right)$. CAM-3003 administration affected few genes with only three being changed compared to the CAT-004 isotype control and an additional 20 genes relative to the PBS control (Additional file 4). Retnla (Fizz1) and Ear1 were decreased and $C d 36$ increased in CAM-3003-treated vs. CAT-treated cells. Any KEGG pathway enrichment was again driven by single gene changes. With this approach in the AIP model, GM-CSF, at least at the time point examined, once more made only a minor contribution to the gene expression changes in monocyte-derived cells (but see "Discussion"). Decreased gene expression of Retnla and increased gene expression of Cd36 following 

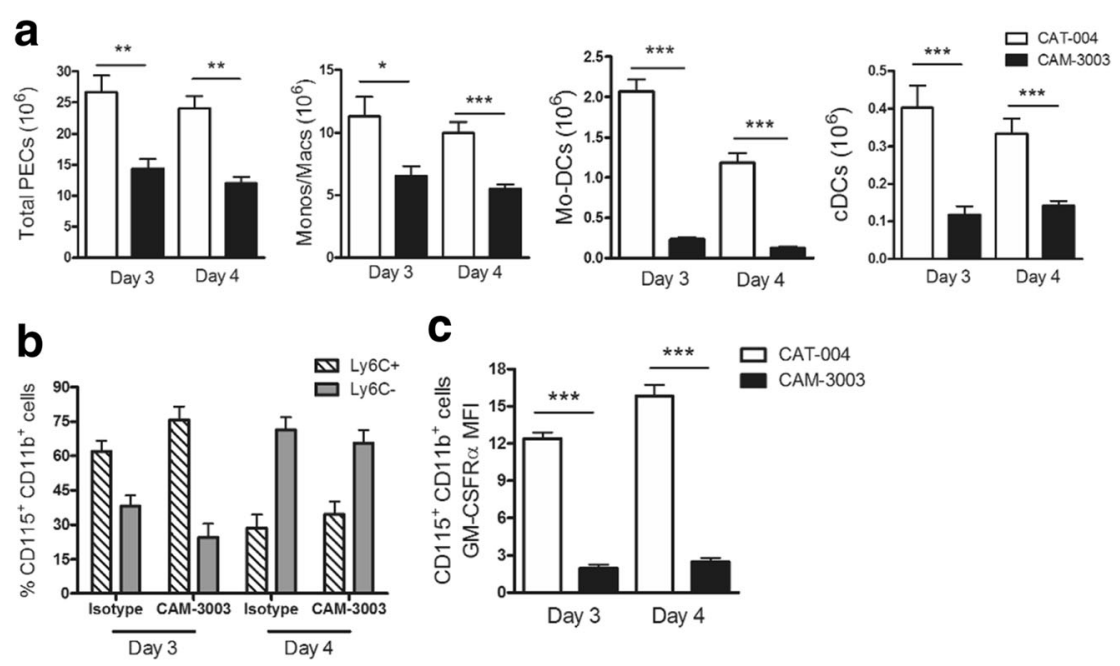

C
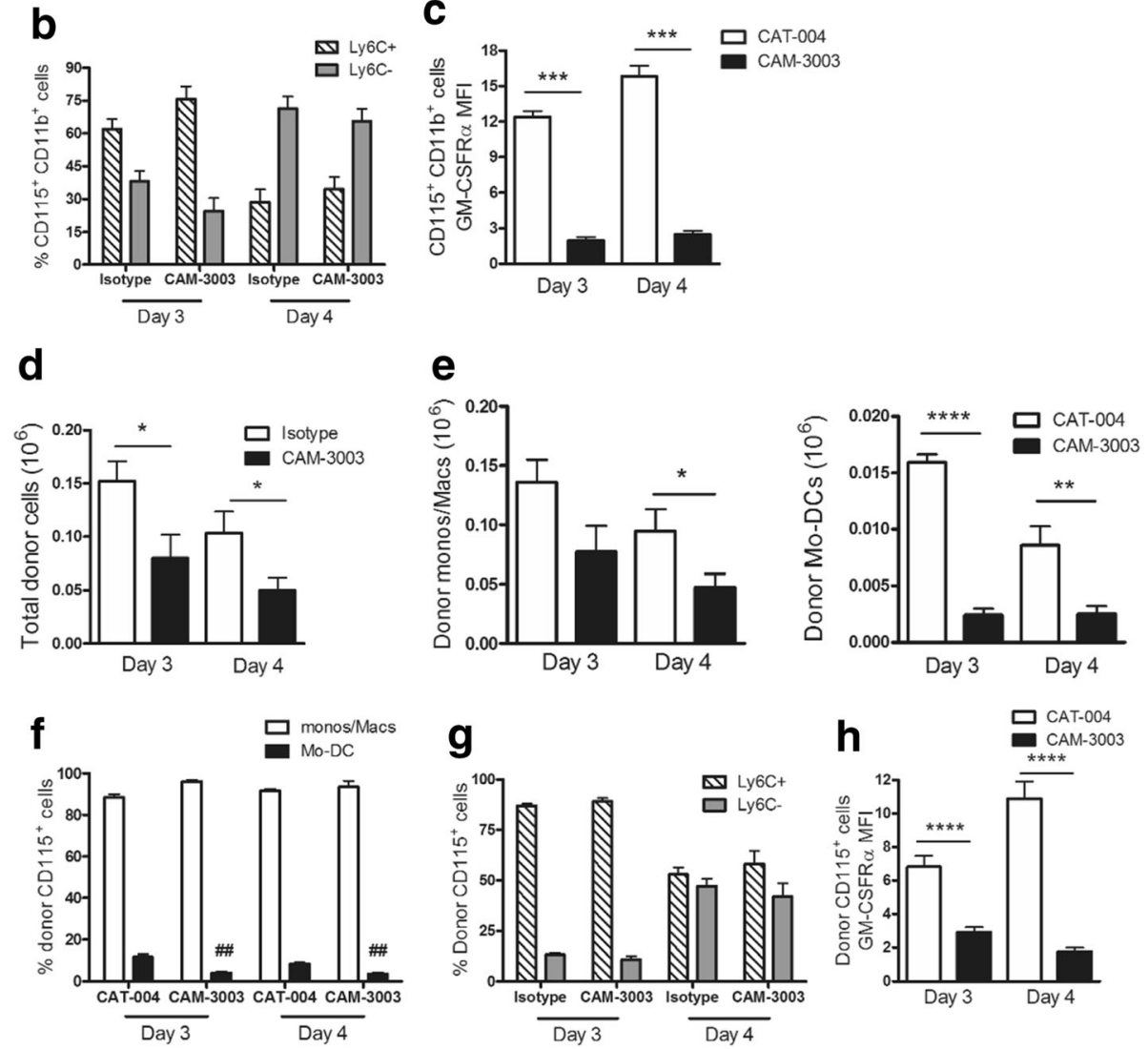

Fig. 5 Granulocyte macrophage colony-stimulating factor receptor a (GM-CSFRa) blockade suppresses generation of monocyte-derived dendritic cells (Mo-DCs) from donor monocytes in the antigen-induced peritonitis (AIP) cavity. CD $115^{+}$MacGreen bone marrow cells were adoptively transferred intraperitoneally (i.p.) to C57BL/6 wild-type (WT) mice on day 2 following AlP induction. C57BL/6 mice were treated i.p. with CAT-004 or CAM-3003 at the same time as the CD115+ cell transfer. Peritoneal exudate cells (PECs) were harvested on day 3 and day 4 post AIP induction, i.e., one or two days, respectively, following CD115 cell transfer and monoclonal antibody (mAb) treatment. a Total cells, monocytes/macrophages (CD11 $\mathrm{C}^{-} \mathrm{MHCII}^{+-}$), Mo-DCs and conventional dendritic cells (CDCs) (host and donor cells). b Percentage of CD115 ${ }^{+} \mathrm{CD} 11 \mathrm{~b}^{+}$cells that are Ly6C ${ }^{+}$vs. Ly6C (host and donor cells). c GM-CSFRa expression (mean fluorescence intensity (MFI)) on CD115 $5^{+}$CD11 b ${ }^{+}$cells

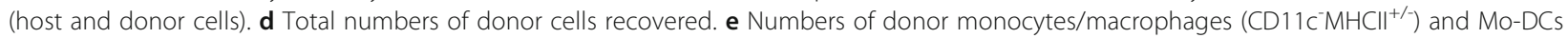
recovered. $\mathbf{f}$ Percentage of recovered donor cells that are monocytes/macrophages $\left(\mathrm{CD} 11 \mathrm{C}^{-} \mathrm{MHCI}{ }^{+/}\right)$and Mo-DCs. $\mathbf{g}$ Percentage of recovered donor cells that are Ly6C ${ }^{+}$vs. Ly6C. $\mathbf{h}$ GM-CSFRa expression (MFI) on recovered donor cells. Data are expressed as mean \pm SEM; $n=8$ mice/ group; ${ }^{*} p<0.05,{ }^{* *} p<0.01,{ }^{* * *} p<0.001,{ }^{* * *} p<0.0001$, CAM-3003 vs. CAT-004; ${ }^{\# \#} p<0.01$, CAM-3003 vs. CAT-004

GM-CSFR $\alpha$ blockade in total PECs from a day 4 AIP model was confirmed by quantitative PCR (data not shown).

\section{GM-CSFR signalling in monocytes regulates Mo-DC/ macrophage numbers in the AIP model}

In order to test whether GM-CSF in the AIP peritoneum was acting directly via its receptor on the incoming monocytes, Csf $2 \mathrm{rb}^{-/} \mathrm{Csf} 2 \mathrm{rb2}^{-/}$(CD45.2) donor monocytes $\left(\mathrm{CD} 115^{+}\right)$ were injected i.p. at day 2 into C57BL/6 WT (CD45.1) mice undergoing AIP. As can be seen in Fig. 6a, at day 4 there were fewer donor monocytes/macrophages (R2 and R3 populations combined) and Mo-DCs if Csf2rb-1Csf $2 \mathrm{rb} 2^{-/-} \mathrm{CD} 115^{+}$bone marrow monocytes were transferred when compared to WT (CD45.2) monocyte transfer; interestingly, the proportion of the monocytes/ macrophages and Mo-DCs recovered from the donor monocytes did not differ between the two strains 
(Fig. 6b), i.e., there was not a proportional loss in donor Mo-DCs in contrast to the data above wherein i.p. CAM-3003 preferentially reduced the donor monocyte to Mo-DC conversion (Fig. 5f). It can also be noted that the loss of Ly6C from the donor monocytes from WT and $C s f 2 r b^{-/-} C s f 2 r b 2^{-/-}$mice was similar (Fig. 6c). The total number of $\mathrm{CD} 115^{+}$(R1-R3 populations) cells recovered in the recipient mice was not influenced by the strain of the monocyte donor (data not shown). Thus, direct GM-CSF signalling appears important for maintenance of cell number but not for the differentiation of monocytes into Mo-DCs, at least when certain markers are used (see "Discussion").

\section{Discussion}

In the AIA model we were able to show that anti-GMCSF mAb, both prophylactically and therapeutically, could ameliorate arthritis, in particular the later structural changes. These data extend our findings with GM$\mathrm{CSF}^{-/-}$mice [25] in this model and extend the number of inflammation models where GM-CSF neutralization is effective [1, 2, 35]. In contrast, neither an anti-CSF-1R $\mathrm{mAb}$ nor an anti-CSF-1 mAb reduced arthritis, suggesting lack of involvement of CSF-1 and IL-34, and possibly reflecting the high neutrophil component and the relatively acute nature of the model compared with other more chronic and more macrophage-dependent arthritis models where such blockade was effective [45-47].

We took advantage of the anti-GM-CSFR $\alpha$ mAb (CAM-3003) to explore GM-CSFR $\alpha$ expression in the AIA model and the effect of GM-CSFR $\alpha$ blockade on synovial myeloid populations. The anti-GM-CSFR $\alpha$ mAb easily detected the surface GM-CSFR $\alpha$ on each of the F4/80 ${ }^{+}$MPS populations, monocytes and cDCs, but only low levels were found on neutrophils and eosinophils. GM-CSFR $\alpha$ blockade was successful at reducing the numbers of $\mathrm{F} 4 / 80^{+}$MPS cells and eosinophils. This observation could be clinically relevant because macrophage numbers in RA synovial tissue have been found to correlate with disease activity and it has been speculated that GM-CSF may be controlling such numbers [48]. Interestingly, among F4/80 ${ }^{+}$cells, Mo-DCs, defined here as $\mathrm{MHCII}^{+} \mathrm{CD} 11 \mathrm{c}^{+}$cells, was the only population with significantly lower numbers following anti-GM-CSFR $\alpha$ $\mathrm{mAb}$ treatment indicating a preferential reduction. Prior to the availability of CAM-3003 to measure surface murine GM-CSFR $\alpha$ directly and therefore easily, a chimeric protein containing the Fc-fragment of human IgG1 coupled to murine GM-CSF was the method available to measure it on myeloid populations [49].

TNF and IL- 6 have been implicated in the AIA model using mAb neutralization or gene-deficient mice, albeit with variable degrees of efficacy [19-24]. Following anti-TNF or anti-IL-6 mAb treatment, unlike that of anti-GM-CSFR $\alpha$ mAb, we found no preferential reduction of Mo-DCs and eosinophils, but an effect on the numbers of $\mathrm{Gr}-1^{+}$synovial monocytes; these data suggest that GM-CSF has a different mode of action in this model than TNF and IL-6, with possible implications for the trials targeting GM-CSF or its receptor [2]. It is possible that higher doses of anti-TNF and anti-IL-6 mAbs may have also led to a preferential reduction of Mo-DCs and eosinophils, although they were high compared to those used in other murine inflammation models [50, 51].

We also took advantage again of our convenient AIP model to explore further, using the anti-GM-CSFR $\alpha$ $\mathrm{mAb}$ approach, the role of GM-CSF in inflammation $[28,32]$. This model has been viewed as a relevant, antigen-driven inflammation model to study resolutionphase macrophages given its particularly acute nature [52]. In both the AIA and AIP models, the relative surface GM-CSFR $\alpha$ expression of the myeloid populations was similar as was the preferential Mo-DC reduction
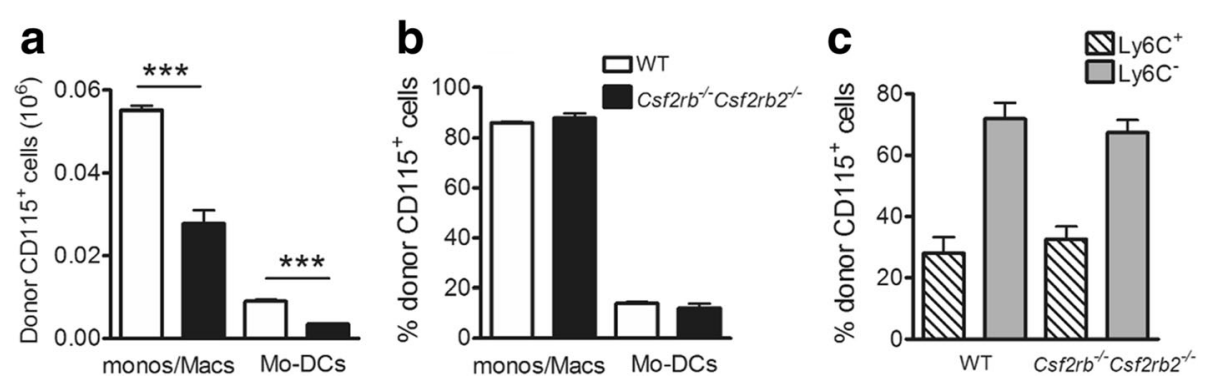

Fig. 6 In antigen-induced peritonitis (AIP), granulocyte macrophage colony-stimulating factor receptor (GM-CSFR) signalling in monocytes directly regulates monocyte/macrophage/monocyte-derived dendritic cell (Mo-DC) numbers but not Mo-DC development. CD $115^{+}$bone marrow monocytes from Csf2rb ${ }^{-1} \mathrm{Csf2}_{2} \mathrm{r}_{2}^{-1-}$ or C57BL/6 wild-type (WT) mice (both CD45.2) were adoptively transferred intraperitoneally (i.p.) to C57BL/6 (CD45.1) mice on day 2 following AIP induction. Peritoneal exudate cells (PECs) were harvested on day 4, i.e., two days following CD115 cell transfer. a Numbers of donor monocytes/macrophages and Mo-DCs. b Percentage of donor cells that are monocytes/macrophages and Mo-DCs. c Percentage of donor cells that are Ly6C ${ }^{+}$vs. Ly6C. Data are expressed as mean \pm SEM; $n=5-7$ mice/group; *** $p<0.001$, WT vs. Csf2rb ${ }^{-1} \mathrm{Csf}_{\mathrm{r} b 2}{ }^{-1}$ donor cells 
amongst the MPS cells upon anti-GM-CSFR $\alpha$ administration. GM-CSFR $\alpha$ blockade had a significant effect on PEC numbers, whereas TNF and IL-6 depletion did not. As for murine collagen-induced arthritis [11,33, 36], the effect on myeloid cell numbers in peritonitis upon GMCSFR $\alpha$ blockade reported above was similar to that previously observed following ligand neutralization [28].

By allowing direct injection of donor monocytes into the inflamed site, the AIP model also enabled us to conclude that GM-CSF signalling in the peritoneal cavity itself was contributing to the increased numbers of inflammatory Mo-DCs and monocytes/macrophages which were shown previously to originate from infiltrating monocytes [28]. We were also able to demonstrate that GM-CSFR signalling in donor monocytes themselves regulates macrophage/Mo-DC numbers; whether this is due to a pro-survival function of GMCSF and/or to its ability to retain cells in the cavity is unknown. In contrast, mixed bone marrow chimeras lacking functional GM-CSFR in one donor population showed that equal numbers of Mo-DCs from WT and Csf2 $r^{-/}$mice were present in the inflamed central nervous system (CNS) in experimental autoimmune encephalomyelitis [3]; similarly, monocytes from WT and Csf2 $r^{-1-} \mathrm{Csf2} 2 \mathrm{rb2}^{-1-}$ mice were able to differentiate into Mo-DCs in equal numbers in the lungs and lungdraining lymph nodes when adoptively transferred intravenously into mice infected intranasally with influenza virus [3].

Given the preferential depletion of Mo-DCs by both anti-GM-CSF [28] and anti-GM-CSFR $\alpha$ administration in the AIP model (Fig. 3b and c), it might have been expected that there would have been a preferential dependence for Mo-DC generation on GM-CSFR signalling in the donor monocytes. However, direct GM-CSFR signalling was not required for the differentiation of monocytes into Mo-DCs in the AIP cavity as, despite there being fewer recoverable CD115 ${ }^{+} \mathrm{Csf} 2 \mathrm{r}^{-/} \mathrm{Csf} 2 \mathrm{rb} 2^{-/-}$ donor MPS cells compared to CD115 ${ }^{+}$WT donor MPS cells, the proportion of these donor MPS cells that had differentiated into Mo-DCs was similar between the two strains, noting that in this case the WT host cells are still able to respond to GM-CSF; the reason for this result is unclear, although it suggests an indirect GM-CSF-dependent mechanism, at least for the upregulation of the CD11c and MHCII surface markers used to define Mo-DCs.

The AIP model also enabled us to demonstrate numerous changes in gene expression between monocytes and their progeny in the inflamed peritoneal cavity. Even though the experiments above were not able to demonstrate a dramatic GM-CSF-dependence for these transcriptomic changes, it is possible that similar analyses at earlier time points may be more fruitful [52]; however, it could be that GM-CSF control over cell numbers may of itself be quite an important component of GM-CSFdependent inflammation [27, 28, 48].

\section{Conclusions}

In summary, we show for the first time during inflammation that GM-CSFR $\alpha$ neutralization leads to similar changes in myeloid populations as GM-CSF neutralization [28], with local GM-CSF signalling in MPS cells being important for the regulation of inflammatory macrophage/ Mo-DC numbers. Our observations suggest that GM-CSF blockade modulates inflammatory responses differently to TNF or IL-6 blockade and may provide a greater understanding of how GM-CSFR $\alpha$ /GM-CSF inhibition is effective in RA; they may also help identify additional diseases where targeting this pathway may provide benefit.

\section{Additional files}

\begin{abstract}
Additional file 1: A Representative FACS plots showing Ly6G and Ly6C staining of $\mathrm{CD} 45^{+}$myeloid populations in the AIA knee joint. $\mathrm{F} 4 / 80^{\text {int }} \mathrm{SSC} \mathrm{C}^{\text {h }}$ eosinophils (Eos), F4/80+ $\mathrm{CD} 11 \mathrm{C}^{+} \mathrm{MHCl}{ }^{+} \mathrm{Mo}-\mathrm{DCS}(\mathrm{R} 1), \mathrm{F} 4 / 80^{+} \mathrm{CD} 11 \mathrm{C}^{-} \mathrm{MHCl}{ }^{+}$ macrophages (Macs) (R2), F4/80 ${ }^{+} \mathrm{CD} 11 \mathrm{C}^{-} \mathrm{MHCI}^{-}$macrophages (R3), F4/80-

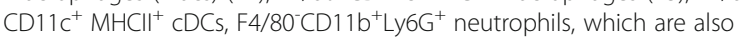

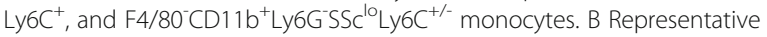
FACS plots of $C D 45^{+}$myeloid populations in the AIA knee joint showing $\mathrm{Ly}_{6 \mathrm{G}^{+}}$neutrophils are CD64 and $\mathrm{F} 4 / 80^{+}$macrophages/Mo-DCs are CD64 ${ }^{+}$. (PDF 235 kb)
\end{abstract}

Additional file 2: Representative FACS plots showing the gating strategy used to identify populations in AIP. Ly6G ${ }^{+}$neutrophils (Neutro),

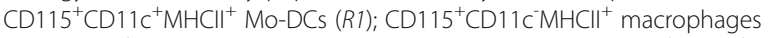
(R2); $\mathrm{CD}_{115^{+} \mathrm{CD} 11 \mathrm{C}^{-} \mathrm{MHCll}}^{-}$monocytes (R3), CD115 Ly6G CD11 $^{+} \mathrm{MHCl}^{+}$

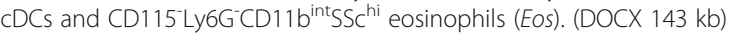

Additional file 3: Genes significantly changed in $\mathrm{CD}_{11} 5^{+}$cells from day 4 AIP following CAM-3003, CAT-004 or PBS treatment (day -1). CD115 PECs were sorted from the peritoneal cavity of C57BL/6 on day 4 and subjected to microarray analysis. Highlighted genes were increased in CAM-3003 vs. CAT-004-treated mice; all other genes were decreased in CAM-3003- vs. CAT-004- or PBS-treated mice. (PDF 25 kb)

Additional file 4: Genes significantly changed in CD115 ${ }^{+}$CD45.1 donor cells from day 4 AIP. C57BL/6 CD45.1 CD 115 $5^{+}$monocytes were transferred on day 2 into C57BL/6 CD45.2 recipient mice treated with CAM-3003, CAT-004 or PBS following AIP induction. CD115 ${ }^{+}$CD45.1 donor cells were sorted on day 4 and subjected to microarray analysis. Highlighted genes were increased in CAM-3003 vs. CAT-004-treated mice; all other genes were decreased in CAM-3003- vs. CAT-004- or PBS-treated mice. (PDF $15 \mathrm{~kb}$ )

Additional file 5: Array data supporting Additional file 3. Data shown as normalised intensities. (XLSX $13054 \mathrm{~kb}$ )

Additional file 6: Array data supporting Additional file 4. Data shown as normalised intensities. (XLSX $11003 \mathrm{~kb}$ )

\section{Abbreviations}

AIA: antigen-induced arthritis; AIP: antigen-induced peritonitis; CDCs: conventional dendritic cells; CFA: complete Freund's adjuvant; FACS: fluorescence-activated cell sorting; GM-CSF: granulocyte macrophage colony-stimulating factor; GM-CSFRa: granulocyte macrophage colony-stimulating factor receptor a - subunit; H\&E: haematoxylin and eosin; i.a.: intra-articular; IL: interleukin; i.p.: intraperitoneal; KEGG: Kyoto Encyclopedia of Genes and Genomes; mAbs: monoclonal antibodies; mBSA: methylated bovine serum albumin; Mo-DCs: monocyte-derived dendritic cells; MPS: mononuclear phagocyte system; PBS: phosphate-buffered saline; PECs: peritoneal exudate cells; PG: proteoglycan; RA: rheumatoid arthritis; TNF: tumour necrosis factor; WT: wild-type 


\section{Acknowledgements}

Not applicable.

\section{Funding}

ADC and JAH were supported in part from grants (1032147) and JAH by a Senior Principal Research Fellowship from the National Health and Medical Research Council of Australia.

\section{Availability of data and materials}

The datasets generated and/or analysed during the current study are available from the corresponding author on reasonable request. Additional file 5 contains the array data supporting Additional file 3. Additional file 6 contains the array data supporting Additional file 4

\section{Authors' contributions}

ADC participated in the design and coordination of the study and interpretation of data, performed the statistical analysis and drafted the manuscript. CL carried out the in vivo animal experiments, analysed the data and helped to revise the manuscript. MJR participated in the design of the study and interpretation of data, participated in the microarray studies and helped to revise the manuscript, RS carried out the in vivo arthritis experiments, analysed the data and helped to revise the manuscript. MAS participated in the design of the study and interpretation of data and helped to revise the manuscript. JAH participated in the design and coordination of the study and interpretation of data and drafted the manuscript. All authors read and approved the final manuscript.

\section{Competing interests}

This work was supported by Medlmmune, a subsidiary of AstraZeneca. MJR and MAS were salaried employees of Medlmmune during the study. The authors declare that they have no competing interests.

\section{Consent for publication}

Not applicable.

\section{Ethics approval and consent to participate}

Experiments were approved by The University of Melbourne Animal Ethics Committee.

\section{Author details}

'Department of Medicine, Royal Melbourne Hospital, University of Melbourne, Parkville, Victoria 3050, Australia. ${ }^{2}$ Department of Respiratory, Inflammation and Autoimmunity, Medlmmune Ltd, Granta Park, Cambridge CB21 6GH, UK. ${ }^{3}$ Present Address: Regeneron, 777 Old Saw Mill River Rd, Tarrytown, NY, USA.

Received: 1 August 2016 Accepted: 16 November 2016 Published online: 01 December 2016

\section{References}

1. Hamilton JA, Achuthan A. Colony stimulating factors and myeloid cell biology in health and disease. Trends Immunol. 2013;34:81-9.

2. Hamilton JA. GM-CSF as a target in inflammatory/autoimmune disease: current evidence and future therapeutic potential. Expert Rev Clin Immunol. 2015;11:457-65.

3. Greter M, Helft J, Chow A, Hashimoto D, Mortha A, Agudo-Cantero J, Bogunovic M, Gautier EL, Miller J, Leboeuf M, Lu G, Aloman C, Brown BD, Pollard JW, Xiong H, Randolph GJ, Chipuk JE, Frenette PS, Merad M. GM-CSF controls nonlymphoid tissue dendritic cell homeostasis but is dispensable for the differentiation of inflammatory dendritic cells. Immunity. 2012;36: $1031-46$.

4. Xu Y, Zhan Y, Lew AM, Naik SH, Kershaw MH. Differential development of murine dendritic cells by GM-CSF versus Flt3 ligand has implications for inflammation and trafficking. J Immunol. 2007;179:7577-84.

5. Ko HJ, Brady JL, Ryg-Cornejo V, Hansen DS, Vremec D, Shortman K, Zhan Y, Lew AM. GM-CSF-responsive monocyte-derived dendritic cells are pivotal in Th17 pathogenesis. J Immunol. 2014;192:2202-9.

6. Segura E, Touzot M, Bohineust A, Cappuccio A, Chiocchia G, Hosmalin A, Dalod $M$, Soumelis V, Amigorena S. Human inflammatory dendritic cells induce Th17 cell differentiation. Immunity. 2013;38:336-48.
7. Naik SH, Metcalf D, van Nieuwenhuijze A, Wicks I, Wu L, O'Keeffe M, Shortman K. Intrasplenic steady-state dendritic cell precursors that are distinct from monocytes. Nat Immunol. 2006;7:663-71.

8. Zhan Y, Vega-Ramos J, Carrington EM, Villadangos JA, Lew AM, Xu Y. The inflammatory cytokine, GM-CSF, alters the developmental outcome of murine dendritic cells. Eur J Immunol. 2012;42:2889-900.

9. Campbell IK, van Nieuwenhuijze A, Segura E, O'Donnell K, Coghill E, Hommel M, Gerondakis S, Villadangos JA, Wicks IP. Differentiation of inflammatory dendritic cells is mediated by NF-kB1-dependent GM-CSF production in CD4 T cells. J Immunol. 2011;186:5468-77.

10. Hansen G, Hercus TR, MCClure BJ, Stomski FC, Dottore M, Powell J, Ramshaw H, Woodcock JM, Xu Y, Guthridge M, McKinstry WJ, Lopez AF, Parker MW. The structure of the GM-CSF receptor complex reveals a distinct mode of cytokine receptor activation. Cell. 2008;134:496-507.

11. Greven DE, Cohen ES, Gerlag DM, Campbell J, Woods J, Davis N, van Nieuwenhuijze A, Lewis A, Heasmen S, McCourt M, Corkill D, Dodd A, Elvin J, Statache G, Wicks IP, Anderson IK, Nash A, Sleeman MA, Tak PP. Preclinical characterisation of the GM-CSF receptor as a therapeutic target in rheumatoid arthritis. Ann Rheum Dis. 2015;74:1924-30.

12. Brackertz D, Mitchell GF, Mackay IR. Antigen-induced arthritis in mice. I. Induction of arthritis in various strains of mice. Arthritis Rheum. 1977;20: $841-50$.

13. Kruijsen MW, van den Berg WB, van de Putte LB. Sequential alterations of periarticular structures in antigen-induced arthritis in mice. Histological observations on fibrous capsule, ligaments, bone and muscles, using whole joint sections. Br J Exp Pathol. 1983;64:298-305.

14. van den Berg $W B$, van de Putte $L B$, Zwarts WA, Joosten $L A$. Electrical charge of the antigen determines intraarticular antigen handling and chronicity of arthritis in mice. J Clin Invest. 1984;74:1850-9.

15. Petrow PK, Thoss K, Henzgen S, Katenkamp D, Brauer R. Limiting dilution analysis of the frequency of autoreactive lymph node cells isolated from mice with antigen-induced arthritis. J Autoimmun. 1996;9:629-35.

16. Engdahl C, Lindholm C, Stubelius A, Ohlsson C, Carlsten H, Lagerquist MK. Periarticular bone loss in antigen-induced arthritis. Arthritis Rheum. 2013;65: 2857-65.

17. Weiss M, Byrne AJ, Blazek K, Saliba DG, Pease JE, Perocheau D, Feldmann M, Udalova IA. IRF5 controls both acute and chronic inflammation. Proc Natl Acad Sci USA. 2015;112:11001-6.

18. Simon J, Surber R, Kleinstauber G, Petrow PK, Henzgen S, Kinne RW, Brauer R. Systemic macrophage activation in locally-induced experimental arthritis. J Autoimmun. 2001;17:127-36.

19. van de Loo FA, Joosten LA, van Lent PL, Arntz OJ, van den Berg WB. Role of interleukin-1, tumor necrosis factor alpha, and interleukin-6 in cartilage proteoglycan metabolism and destruction. Effect of in situ blocking in murine antigen- and zymosan-induced arthritis. Arthritis Rheum. 1995;38:164-72.

20. Ohshima S, Saeki Y, Mima T, Sasai M, Nishioka K, Nomura S, Kopf M, Katada Y, Tanaka T, Suemura M, Kishimoto T. Interleukin 6 plays a key role in the development of antigen-induced arthritis. Proc Natl Acad Sci USA. 1998;95:8222-6.

21. Boe A, Baiocchi M, Carbonatto M, Papoian R, Serlupi-Crescenzi O. Interleukin 6 knock-out mice are resistant to antigen-induced experimental arthritis. Cytokine. 1999;11:1057-64.

22. de Hooge AS, van de Loo FA, Bennink MB, de Jong DS, Arntz OJ, Lubberts $E$, Richards $C D$, vandDen Berg WB. Adenoviral transfer of murine oncostatin $M$ elicits periosteal bone apposition in knee joints of mice, despite synovial inflammation and up-regulated expression of interleukin-6 and receptor activator of nuclear factor-kappa B ligand. Am J Pathol. 2002;160:1733-43.

23. Wong PK, Quinn JM, Sims NA, van Nieuwenhuijze A, Campbell IK, Wicks IP. Interleukin-6 modulates production of T lymphocyte-derived cytokines in antigen-induced arthritis and drives inflammation-induced osteoclastogenesis. Arthritis Rheum. 2006;54:158-68.

24. Oliveira MC, Tavares LP, Vago JP, Batista NV, Queiroz-Junior CM, Vieira AT, Menezes GB, Sousa LP, van de Loo FA, Teixeira MM, Amaral FA, Ferreira AV. Tumor necrosis factor, but not neutrophils, alters the metabolic profile in acute experimental arthritis. PLoS One. 2016;11, e0146403.

25. Cook AD, Pobjoy J, Sarros S, Steidl S, Durr M, Lacey DC, Hamilton JA. Granulocyte-macrophage colony-stimulating factor is a key mediator in inflammatory and arthritic pain. Ann Rheum Dis. 2013;72:265-70.

26. Cook AD, Braine EL, Hamilton JA. The phenotype of inflammatory macrophages is stimulus dependent: implications for the nature of the inflammatory response. J Immunol. 2003;171:4816-23. 
27. Cook AD, Braine EL, Hamilton JA. Stimulus-dependent requirement for granulocyte-macrophage colony-stimulating factor in inflammation. J Immunol. 2004;173:4643-51.

28. Louis C, Cook AD, Lacey D, Fleetwood AJ, Vlahos R, Anderson GP, Hamilton JA. Specific contributions of CSF-1 and GM-CSF to the dynamics of the mononuclear phagocyte system. J Immunol. 2015;195:134-44.

29. Sasmono RT, Oceandy D, Pollard JW, Tong W, Pavli P, Wainwright BJ, Ostrowski MC, Himes SR, Hume DA. A macrophage colony-stimulating factor receptor-green fluorescent protein transgene is expressed throughout the mononuclear phagocyte system of the mouse. Blood. 2003; 101:1155-63.

30. Scott CL, Robb L, Papaevangeliou B, Mansfield R, Nicola NA, Begley CG. Reassessment of interactions between hematopoietic receptors using common beta-chain and interleukin-3-specific receptor beta-chain-null cells: no evidence of functional interactions with receptors for erythropoietin, granulocyte colonystimulating factor, or stem cell factor. Blood. 2000;96:1588-90.

31. Swierczak A, Cook AD, Lenzo JC, Restall CM, Doherty JP, Anderson RL, Hamilton JA. The promotion of breast cancer metastasis caused by inhibition of CSF-1R/CSF-1 signaling is blocked by targeting the G-CSF receptor. Cancer Immunol Res. 2014;2:765-76.

32. Lenzo JC, Turner AL, Cook AD, Vlahos R, Anderson GP, Reynolds EC, Hamilton JA. Control of macrophage lineage populations by CSF-1 receptor and GM-CSF in homeostasis and inflammation. Immunol Cell Biol. 2012;90:429-40

33. Cook AD, Turner AL, Braine EL, Pobjoy J, Lenzo JC, Hamilton JA. Regulation of systemic and local myeloid cell subpopulations by bone marrow cellderived granulocyte-macrophage colony-stimulating factor in experimental inflammatory arthritis. Arthritis Rheum. 2011;63:2340-51.

34. Irizarry RA, Hobbs B, Collin F, Beazer-Barclay YD, Antonellis KJ, Scherf U, Speed TP. Exploration, normalization, and summaries of high density oligonucleotide array probe level data. Biostatistics. 2003:4:249-64.

35. Hamilton JA. Colony-stimulating factors in inflammation and autoimmunity. Nat Rev Immunol. 2008;8:533-44.

36. Cook AD, Braine EL, Campbell IK, Rich MJ, Hamilton JA. Blockade of collagen-induced arthritis post-onset by antibody to granulocytemacrophage colony-stimulating factor (GM-CSF): requirement for GM-CSF in the effector phase of disease. Arthritis Res. 2001;3:293-8.

37. Williams RO, Feldmann M, Maini RN. Anti-tumor necrosis factor ameliorates joint disease in murine collagen-induced arthritis. Proc Natl Acad Sci USA. 1992;89:9784-8.

38. Wicks IP, Roberts AW. Targeting GM-CSF in inflammatory diseases. Nat Rev Rheumatol. 2016;12:37-48.

39. Hume DA, Mabbott N, Raza S, Freeman TC. Can DCs be distinguished from macrophages by molecular signatures? Nat Immunol. 2013;14:187-9.

40. Murray PJ, Allen JE, Biswas SK, Fisher EA, Gilroy DW, Goerdt S, Gordon S, Hamilton JA, Ivashkiv LB, Lawrence T, Locati M, Mantovani A, Martinez FO, Mege JL, Mosser DM, Natoli G, Saeij JP, Schultze JL, Shirey KA, Sica A, Suttles J, Udalova I, van Ginderachter JA, Vogel SN, Wynn TA. Macrophage activation and polarization: nomenclature and experimental guidelines. Immunity. 2014:41:14-20.

41. Guilliams M, Ginhoux F, Jakubzick C, Naik SH, Onai N, Schraml BU, Segura E, Tussiwand R, Yona S. Dendritic cells, monocytes and macrophages: a unified nomenclature based on ontogeny. Nat Rev Immunol. 2014;14:571-8.

42. Jenkins SJ, Hume DA. Homeostasis in the mononuclear phagocyte system. Trends Immunol. 2014;35:358-67.

43. Smolen JS, Aletaha D. Rheumatoid arthritis therapy reappraisal: strategies, opportunities and challenges. Nat Rev Rheumatol. 2015;11:276-89.

44. Sachs D, Coelho FM, Costa W, Lopes F, Pinho V, Amaral FA, Silva TA, Teixeira AL, Souza DG, Teixeira MM. Cooperative role of tumour necrosis factor-alpha, interleukin-1 beta and neutrophils in a novel behavioural model that concomitantly demonstrates articular inflammation and hypernociception in mice. Br J Pharmacol. 2011;162:72-83.

45. Campbell IK, Rich MJ, Bischof RJ, Hamilton JA. The colony-stimulating factors and collagen-induced arthritis: exacerbation of disease by M-CSF and G-CSF and requirement for endogenous M-CSF. J Leukoc Biol. 2000;68: $144-50$

46. Toh ML, Bonnefoy JY, Accart N, Cochin S, Pohle S, Haegel H, De Meyer M, Zemmour C, Preville X, Guillen C, Thioudellet C, Ancian P, Lux A, Sehnert B, Nimmerjahn F, Voll RE, Schett G. Bone- and cartilage-protective effects of a monoclonal antibody against colony-stimulating factor 1 receptor in experimental arthritis. Arthritis Rheumatol. 2014;66:2989-3000.
47. Garcia S, Hartkamp LM, Malvar-Fernandez B, van Es IE, Lin H, Wong J, Long L, Zanghi JA, Rankin AL, Masteller EL, Wong BR, Radstake TR, Tak PP, Reedquist KA. Colony-stimulating factor (CSF) 1 receptor blockade reduces inflammation in human and murine models of rheumatoid arthritis. Arthritis Res Ther. 2016;18:75

48. Hamilton JA, Tak PP. The dynamics of macrophage lineage populations in inflammatory and autoimmune diseases. Arthritis Rheum. 2009;60:1210-21.

49. Rosas M, Gordon S, Taylor PR. Characterisation of the expression and function of the GM-CSF receptor alpha-chain in mice. Eur J Immunol. 2007; 37:2518-28.

50. Matsumoto I, Zhang H, Yasukochi T, Iwanami K, Tanaka Y, Inoue A, Goto D, Ito S, Tsutsumi A, Sumida T. Therapeutic effects of antibodies to tumor necrosis factor-alpha, interleukin-6 and cytotoxic T-lymphocyte antigen 4 immunoglobulin in mice with glucose-6-phosphate isomerase induced arthritis. Arthritis Res Ther. 2008;10:R66.

51. Lawlor KE, Campbell IK, Metcalf D, O'Donnell K, van Nieuwenhuijze A, Roberts AW, Wicks IP. Critical role for granulocyte colony-stimulating factor in inflammatory arthritis. Proc Natl Acad Sci USA. 2004;101:11398-403.

52. Tomasdottir V, Vikingsson A, Hardardottir I, Freysdottir J. Murine antigeninduced inflammation-a model for studying induction, resolution and the adaptive phase of inflammation. J Immunol Methods. 2014;415:36-45.

\section{Submit your next manuscript to BioMed Central and we will help you at every step:}

- We accept pre-submission inquiries

- Our selector tool helps you to find the most relevant journal

- We provide round the clock customer support

- Convenient online submission

- Thorough peer review

- Inclusion in PubMed and all major indexing services

- Maximum visibility for your research

Submit your manuscript at www.biomedcentral.com/submit
C Biomed Central 